\title{
Cobertura pedológica em topossequência de vertentes na área experimental do departamento de solos/ campus da Universidade Federal de Santa Maria
}

\author{
Pedological cover in slope topossequence in the experimental área of the soil department/ \\ Universidade Federal de Santa Maria Campus
}

\author{
Mauro Kumpfer Werlang ${ }^{1}$, Ronaldo $\mathrm{Facco}^{2}$, Romulo Augusto Aita ${ }^{3}$, Arthur Piccolo Werlang ${ }^{4}$ \\ 1, 2,3,4 Universidade Federal de Santa Maria - Santa Maria - RS - Brasil
}

\begin{abstract}
Resumo
O estudo e a representação cartográfica tridimensionais da cobertura pedológica permitem estudar os processos biogeodinâmicos, o sentido e a evolução da pedogênese, possibilitando assim a reconstituição dos mecanismos responsáveis pelas diferenciações pedológicas. A cobertura pedológica é um sistema estrutural complexo que apreende transformações progressivas das organizações, tanto vertical quanto lateralmente no sentido da vertente, estando intimamente relacionada com os outros elementos da paisagem, especialmente o relevo. Nesta perspectiva, o presente trabalho tem por objetivo geral caracterizar a cobertura pedológica ao longo de uma topossequência de vertentes na tentativa de caracterizar a dinâmica dessas vertentes a partir do comportamento dos volumes pedológicos. Tem como objetivos específicos (1) estabelecer uma compartimentação em uma topossequência de vertentes desde o divisor orográfico até o talvegue demonstrando o comportamento da cobertura pedológica nas secções de vertente; (2) descrever os volumes pedológicos nas secções de vertente e (3) caracterizar algumas propriedades desses volumes pedológicos para avaliar a morfogênese das vertentes. Nesse sentido, considerou-se uma compartimentação numa topossequência constituída por um ARGISSOLO VERMELHO Distrófico arênico situada na área experimental do Departamento de Solos, no Campus da Universidade Federal de Santa Maria. Foram selecionadas duas topossequências e caracterizadas as coberturas pedológicas, bem como o levantamento expedito da topografia das vertentes. O detalhamento da estrutura da cobertura pedológica das vertentes foi realizado através da identificação e caracterização de perfis em trincheiras e por sondagens a trado, de onde foram retiradas amostras. Os horizontes pedogenéticos Ap e A constituíram o volume 1; o horizonte pedogenético E o volume 2; o horizonte pedogenético Bt o volume 3; e, os depósitos aluvionais do talvegue o volume 4. Observou-se um perfil côncavo-convexo, ao considerar-se a conformação da topossequência. Esse perfil evolui de um perfil côncavo, na porção superior da vertente, para um perfil convexo, no setor médio da vertente, evidenciando uma perda por denudação no segmento convexo, fazendo-o evoluir para um perfil convexo. O volume 2 deixa de existir no trecho intermediário da vertente, sendo que, neste setor, se constatou uma ruptura na encosta sugerindo o ponto no qual aflora o fluxo subsuperficial da água. Isso sugere que o volume 2 funciona como facilitador no processo de exfiltração nesse setor da vertente. O setor onde o volume 3 está situado mais próximo da superfície indica a remoção do volume 1 configurando um declive convexo nesse segmento da vertente. Concluiu-se que a maior perda por denudação acontece nos segmentos côncavos das vertentes. Pode ainda concluir que a concavidade apresentada nos segmentos do perfil da vertente está relacionada com a exfiltração da água em face das propriedades apresentadas pelos volumes pedológicos. Por fim, conclui-se que a cobertura pedológica exerce influência na conformação do perfil dessas vertentes.

Palavras chaves: vertentes; perfil e forma; evolução morfogenética.
\end{abstract}

\begin{abstract}
The study and the three-dimensional cartographic representation of the pedological cover allows to study biogeodinamic processes, the sense and the evolution of pedogenesis, reconstituting the mechanisms responsible for the pedological differenciation. The pedological cover is a complex structural system that includes progressive transformations of the organizations, vertically and laterally towards the shed, being closely related to the others elements of the landscape, specially the relief. In this way, the present study aims a pedological cover characterization along a topossequence of strands, trying to characterize the dynamic of this strands from the analysis of the pedological volumes. The specific objectives are (1) to establish a subdivision in a toposequence of strands since the orographic divider to the thalweg, showing the behavior of the pedological cover in sections of slope; (2) to describe the pedological volumes in the sections of slope and (3) to characterize some properties of this pedological volumes to evaluate the morfogenesis of slopes. In this sense, was considered a compartimentation in a topossequence consisting by a distrophic RED ARGISSOIL located in the experimental area of the Soil Department, in the campus of the Universidade Federal de Santa Maria. There was selected two topossequences and characterized the pedological cover, such as the survey of the slopes topography. The detailment of the slope pedological cover structure was realized by identification and characterization of profiles in trenches and polls the auger from the place where the samples were collected. The Ap and A pedogenetical horizonts constitue the 1 volume; the pedogenetical horizont $E$ the 2 volume; the pedogenetical horizont Bt the 3 volume; and, the aluvional deposits of the thalweg the 4 volume. It was observed a convex-concave profile when considering the conformation of the topossequence. This profile evolves from a concave profile, in the superior section of the slope, to a convex profile, in the medium section of the slope, showing a loss by denudation in the convex segment, making it to evolve into a convex profile. The 2 volume no longer exists in the intermediate position of the strand, and in this sector was found a break in the hill, suggesting the point where the subsurface water flow comes. This suggests that the 2 volume works as a facilitator in the exfiltration process in this part of the slope. The sector where the 3 volume is located closer to the surface indicates the removal of the 1 volume, making a convex hill in this part of the slope. So, the largest loss by denudation happens in the concave segments of the slopes. It can be conclude, too, that the concavity showed in the slope segments profile is related to the water exfiltration because the proprieties presented by the pedological volumes. Finally, it is concluded that the pedological cover influences the profile conformation of these slopes.
\end{abstract}

Keywords: slopes, profile and shape, morphogenetic evolution. 


\section{Introdução}

Nas últimas décadas, o Planeta tem apresentado transformações em proporções e escala muito maior do que as registradas em toda sua história. Neste contexto, a década de 70 marca a implantação em nível mundial de um novo paradigma: o tecnológico, o qual se manifestou abalando e provocando crises sociais e declínio nas estruturas econômicas de muitos países, em função, principalmente, da desvalorização do patrimônio natural ou dos recursos naturais clássicos e das atividades a eles relacionados.

Atualmente, as transformações mais significativas concentram-se em grandes eixos (informática, biotecnologia, energia, telecomunicações, entre outros) os quais exercem influência sobre os demais e, concomitantemente, orientam o desenvolvimento econômico mundial. Entretanto, o avanço tecnológico não pode prescindir do patrimônio natural. Assim sendo, os recursos naturais continuam sendo imprescindíveis para manutenção da sociedade e a base do desenvolvimento econômico, inclusive nos países industrializados.

Diante do paradigma, representado principalmente pelas revoluções industrial e tecnológica, associadas às novas e crescentes necessidades sociais, desencadeou-se uma profunda mudança na forma de exploração e uso dos recursos naturais, ou seja, as explorações tornaram-se mais intensivas e agressivas, provocando a rápida degradação dos recursos naturais, sendo uma das mais expressivas, a degradação dos solos.

Tratando-se particularmente do solo, o aumento das áreas de plantio associado ao processo de modernização da atividade agrícola, com o uso intenso de maquinarias e produtos químicos, levou a uma progressiva degradação deste importante recurso. Com o aumento das áreas de plantio e do uso intenso de maquinarias e produtos químicos, sem a devida orientação e recomendação técnica, registra-se, hoje, uma gama preocupante de fenômenos e conflitos ambientais. Esses conflitos influenciam na dinâmica natural da paisagem e dos solos, acarretando, consequentemente, a perda da fertilidade, a aceleração e intensificação dos processos erosivos e, em algumas áreas, até mesmo desertificação (DREW, 1998).

Problemas ambientais relacionados aos solos, que já perduram há algumas décadas, instigaram e ainda hoje incentivam a realização de pesquisas e a proposição de novas metodologias de estudo do solo com o intuito de compreender, de forma abrangente e completa, sua organização e a estrutura da cobertura pedológica.

A concepção do solo como um corpo natural em evolução na paisagem surgiu com o russo Doku- chaev que o considerou originário de uma rocha-mãe (posteriormente, um material de origem) situada em determinada posição do relevo, sujeita à ação do clima e dos organismos ao longo do tempo. Sua publicação sobre os solos negros das estepes russas - o Chernozém (Dokuchaev 1893) representa esse marco histórico.

Avanços relacionados à evolução na compreensão da organização do solo e de metodologias para seu estudo ocorreram quando Milne (1935) apresenou o conceito de catena e introduziu a concepção de lateralidade do solo, onde os perfis verticais de solo sucedem-se numa vertente, ligados como que em cadeia, sendo que os principais fatores responsáveis pelas sucessões de solos numa encosta seriam os processos erosivos, comandados pela topografia. No final da década de 1960, começaram a surgir, no Brasil, pesquisas conjugando solos e relevo em sequências topográficas (Queiroz Neto, 1969) na região de São Carlos, São Paulo. Carvalho (1970) seguiu a mesma diretriz, acrescentando análises micromorfológicas, com a riqueza de informações que essa técnica já revelara em solos africanos com os trabalhos de Chauvel (1972) e Bocquier (1973).

Ainda na década de 1960, ocorreu outro importante avanço com relação à introdução da noção de tridimensionalidade, onde "cada unidade representada por horizontes verticalmente dispostos" ocuparia certo volume no espaço. Entretanto, mantém-se a concepção de que o espaço pedológico seria constituído pela justaposição de perfis verticais de solo. Na década seguinte, seguiram-se importantes trabalhos, os quais passaram a introduzir uma metodologia de análise através da concepção de cobertura pedológica. Não obstante, em algumas pesquisas nacionais pedogênese e morfogênese tenham sido associadas em superfícies mais amplas do que catenas ou vertentes, como a de Lepsch; Buol (1974), a visão da gênese nas publicações tradicionais de pedologia ficou praticamente restrita à mineralogia das argilas em perfis verticais isolados, daí se inferindo mecanismos de evolução pedogenética. Sob esta óptica metodológica, uma quantidade substancial de publicações foi produzida nos nossos diferentes domínios geográficos. Assim, por exemplo, trabalhos como os de Bocquier (1973), Chauvel (1977), Queiroz Neto (1988) e Queiroz Neto (2000), enfatizaram o estudo de topossequências ao longo de encostas realizando análises bidimensionais das coberturas pedológicas, não mais enfatizando o solo como um indivíduo em perfis verticais, mas sim como um continuum recobrindo toda a extensão das encostas.

Cabe destaque também, ainda na década de 1970, a proposta de Boulet (1978) e Boulet et al. (1982) para o estudo e a representação cartográfica tridi- 
mensionais da cobertura pedológica, que permitiram , assim, conforme Queiroz Neto (1988), estudar os processos biogeodinâmicos, o sentido e a evolução da pedogênese; reconstituir os diferentes mecanismos responsáveis pelas diferenciações pedológicas, bem como suas sucessões cronológicas, demonstrando o comportamento e funcionamento atual da cobertura pedológica de uma dada área.

A partir das pesquisas realizadas pelos pedólogos franceses, pode-se perceber que a cobertura pedológica é um sistema estrutural complexo que apresenta transformações progressivas das organizações, tanto vertical quanto lateralmente no sentido da vertente estando intimamente relacionada com os outros elementos da paisagem, especialmente o relevo.

No Brasil, a proposta metodológica de análise estrutural da cobertura pedológica passou a ser empregada no final da década de 70, com o intuito de identificar diferentes sucessões de perfis de solos ao longo de encostas, compreender a gênese e evolução dos solos e das paisagens e ainda "explicar a distribuição dos solos como conseqüência de processos pedogenéticos e morfogenéticos complexos" (QUEIROZ NETO, 1988, p. 416).

As vertentes, juntamente com os interflúvios e os talvegues, são reconhecidas como componentes fundamentais das unidades de relevo. No entanto, quando refere-se à concepção de paisagem, surgem as seguntes questões: como e de que maneira ela se processa; qual o desenvolvimento das formas de relevo, quais as condições iniciais e até que fase se processa a evolução. Convergindo nesse raciocínio, torna-se, portanto, evidente a importância do conhecimento relativo à morfogênese das vertentes a partir do controle exercido pela cobertura pedológica.

Nesta perspectiva, o presente trabalho tem por objetivo geral caracterizar a cobertura pedológica ao longo de uma topossequência de vertentes na tentativa de caracterizar a dinâmica dessas vertentes a partir do comportamento dos volumes pedológicos. Tem como objetivos específicos (1) estabelecer uma compartimentação em uma topossequência de vertentes desde o divisor orográfico até o talvegue demonstrando o comportamento da cobertura pedológica nas secções de vertente; (2) descrever os volumes pedológicos nas secções de vertente e (3) caracterizar algumas propriedades desses volumes pedológicos na tentativa de avaliar a conformação da forma do perfil das vertentes.

O trabalho foi desenvolvido numa área cuja compartimentação topográfica abrange litologias da Formação Santa Maria (Membro Alemoa e Membro Passo das Tropas), na província geomorfológica da Depressão Periférica Sul-riograndense. A área na qual foi desenvolvido o trabalho apresenta forma de relevo com modelado de dissecação. Partiu-se do pressuposto de que esse modelado também está relacionado à natureza do material sedimentar (areia fina, silte, argilas de baixa a média plasticidade, argilas arenosas e argilas siltosas), além da influência das características do manto pedológico. Nesse sentido, considerou-se uma compartimentação numa topossequência, constituída por um ARGISSOLO VERMELHO Distrófico arênico e um PLANOSSOLO HIDROMÓRFICO Eutrófico arênico, situada na área experimental do Departamento de Solos, no Campus da Universidade Federal de Santa Maria.

\section{Materiais e métodos}

\subsection{Descrição geral da área}

O município de Santa Maria-RS, no que se refere ao relevo, reflete a condição da sua posição situada numa área de transição geomorfológica entre os Planaltos e Chapadas da Bacia Sedimentar do Paraná e a Depressão Periférica Sul-riograndense. As atuações dos agentes erosivos morfogenéticos definiram as formas de relevo e estão associados à diversidade litoestrutural da área abrangida pelo município. No que se refere ao clima, de acordo com a classificação de Köppen (1936 apud AYOADE, 1986), a região apresenta domínio climático do tipo $\mathrm{Cfa}$, ou seja, temperado chuvoso e quente, onde se registram temperaturas entre $-3^{\circ} \mathrm{Ce} 18^{\circ} \mathrm{C}$ nos meses mais frios e nos meses mais quentes temperaturas superiores a $22^{\circ} \mathrm{C}$, sem nenhuma estação seca. A figura 1 ilustra a localização da área de estudo em relação ao município e área urbana de Santa Maria, RS.

No contexto da região central do estado do Rio Grande do Sul e da Depressão Periférica Sul-riograndense, é que está situada a área experimental do Departamento de Solos, no Campus da Universidade Federal de Santa Maria. A área há duas décadas vem sendo utilizada para experimentos com o plantio de cultivos anuais como soja, milho e pastagens (aveia e azevém). Essa área está inserida no domínio dos Campos com Capões e Matas Galerias (Vieira, 1984). Nos interflúvios onde os processos erosivos esculpiram colinas alongadas (regionalmente denominadas por coxilhas) sobre litologias paleozóicas da Bacia do Paraná, aparecem solos medianamente profundos e bem drenados, como os Argissolos. Nos talvegues e áreas com predomínio de processos de agradação, ocorrem solos mal drenados como Planossolos e Gleissolos. No que se refere ao aspecto geológico das vertentes selecionadas para o estudo, estas apresen- 


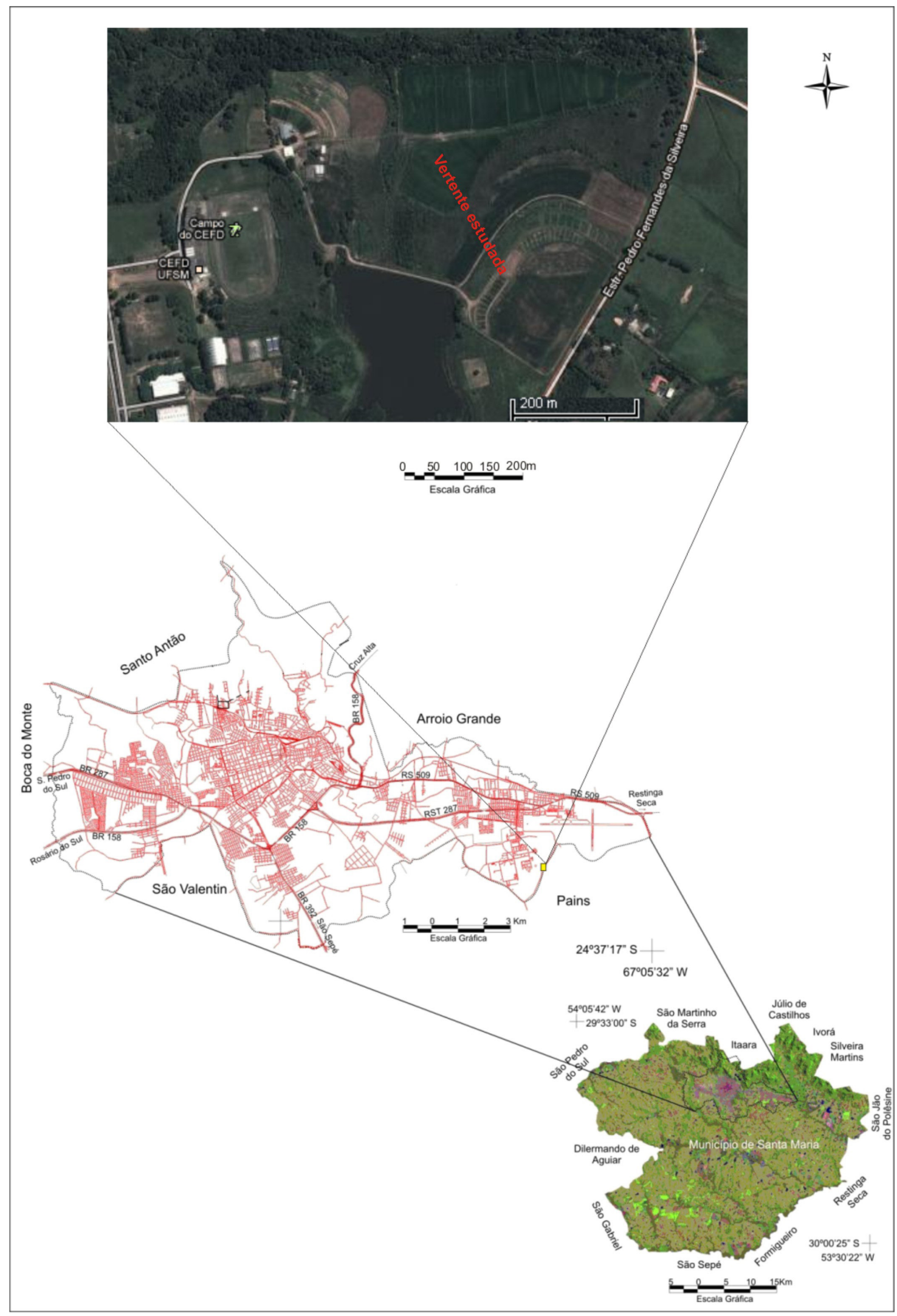

Figura 1: Localização da topossequência de vertente estudada em relação ao município de Santa Maria, RS. Fonte da imagem aérea: http://maps.google.com.br/maps?hl=en\&tab=wl Adaptado (Acesso em 05 maio 2013). 
tam o substrato litológico constituído pela Formação Santa Maria. A vertente identificada como "B" está assentada sobre o substrato litológico do Membro Passo das Tropas constituído predominantemente por arenitos de granulação média a gróssea. A vertente identificada como " $\mathrm{A}$ " assenta-se sobre o Membro Alemoa com litologia predominante de arenitos finos, siltitos, lamitos, argilitos e folhelhos síltico-argilosos.

Em relação à geomorfologia, a área do estudo caracteriza-se pela presença de colinas (coxilhas) suaves e contínuas de baixas altitudes. No Membro Alemoa (onde está situada a vertente A), as coxilhas apresentam-se mais amplas, com ocorrência ocasional de sulcos e ravinas. Onde predomina o Membro Passo das Tropas (onde está situada a vertente B), as vertentes são recobertas por depósitos de terraços fluviais pleistocênicos e, em cota inferior, por depósitos aluvionares nos interflúvios. Neste lugar, também ocorrem sulcos e ravinamentos. Tanto a vertente $\mathrm{A}$ como a B, além de dissecadas por sulcos e ravinas, apresentam canais incisivos que evoluem para os cursos fluviais integrantes da bacia hidrográfica do rio Vacacaí-Mirim.

A área onde foi desenvolvido o trabalho apresenta como cobertura pedológica um ARGISSOLO VERMELHO Distrófico arênico, no terço superior das vertentes, e um PLANOSSOLO HIDROMÓRFICO Eutrófico arênico, no segmento inferior das vertentes junto ao talvegue principal.

\section{Procedimentos metodológicos}

A orientação metodológica do trabalho buscou a adoção da proposição da análise sistêmica da paisagem (Sochava, 1972; Bertrand, 1968, 1971; Monteiro, 2000) e dos níveis de tratamento definidos por Ab'Saber (1969). Classificados em grupos epistemológicos os métodos podem ser indutivos, dedutivos, hipotéticodedutivo, dialético e, fenomenológico.

Para realização do trabalho, fez-se uso do método dedutivo, acreditando-se ser esta uma das formas que permite uma maior proximidade da realidade com a pesquisa. De acordo com os objetivos do trabalho, adotou-se como base teórico-metodológica a proposta de Boulet (1978); e Boulet et al (1979) apud Queiroz Neto (1988), que trata da análise estrutural da cobertura pedológica, buscando-se, assim, a compreensão da bidimensionalidade da dinâmica da cobertura pedológica e a relação com os outros elementos da paisagem.

Para atingir os objetivos propostos, adotou-se como escala de observação os horizontes diagnósticos do solo, a topossequência de vertentes e a paisagem, seguindo-se os seguintes procedimentos (1) reconhecimento geral do comportamento das vertentes da área experimental do Departamento de Solos no Campus da Universidade Federal de Santa Maria, a partir da análise de aerofotogramas verticais; (2) seleção da topossequência a serem caracterizada e (3) detalhamento da estrutura da cobertura pedológica das vertentes, através da identificação e caracterização de perfis de solos em trincheiras e de sondagens a trado.

Os perfis de solos foram descritos conforme as características morfológicas dos horizontes diagnósticos. As características morfológicas visualizadas possibilitaram um agrupamento dos horizontes diagnósticos, definindo-se metodologicamente, para esse trabalho, o que ficou determinado como "volume pedológico". Nesse sentido, os horizontes diagnósticos Ap e A passaram a constituir o volume 1, o horizonte diagnóstico E passou a constituir o volume 2 e, o horizonte diagnóstico Bt passou a constituir o volume 3 . Para a caracterização do volume 4, consideraram-se os depósitos aluvionais situados na secção inferior das vertentes e aqueles situados setor da várzea, próximos ao talvegue.

Desses volumes, foram coletadas amostras deformadas e indeformadas. As coletas das amostras foram feitas sob condições atmosféricas de tempo seco e sem chuva, com o material apresentando condições de umidade que permitissem a coleta de amostras indeformadas. A figura 2 mostra o perfil representativo do ARGISSOLO VERMELHO Distrófico arênico, onde foram descritos os volumes pedológicos e

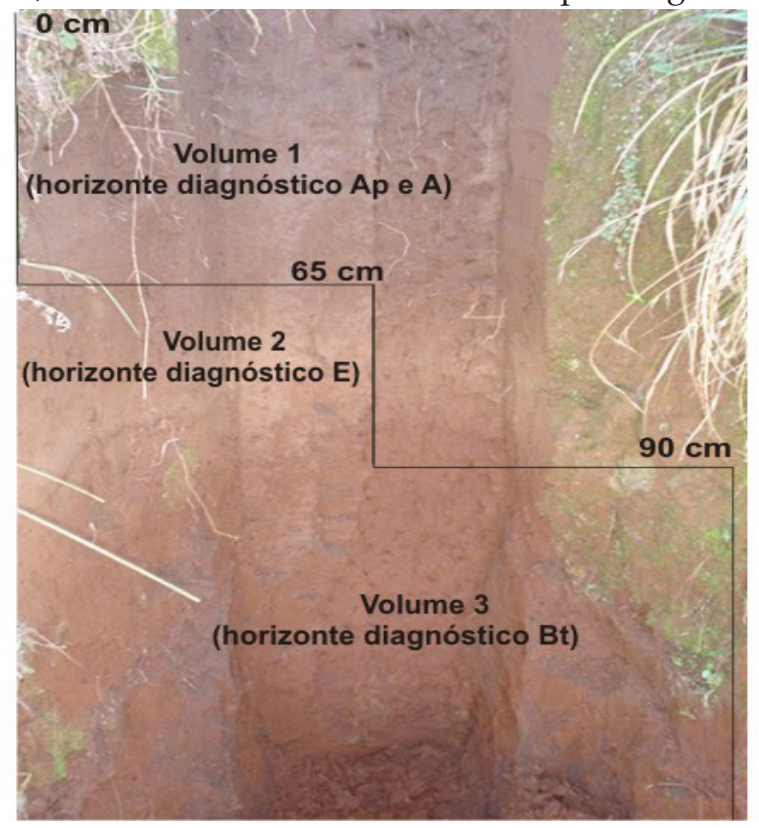

Figura 2: Aspecto da trincheira do perfil representativo de um ARGISSOLO VERMELHO Distrófico arênico, onde foram descritos os volumes pedológicos e retiradas as amostras para a realização dos ensaios no laboratório. 

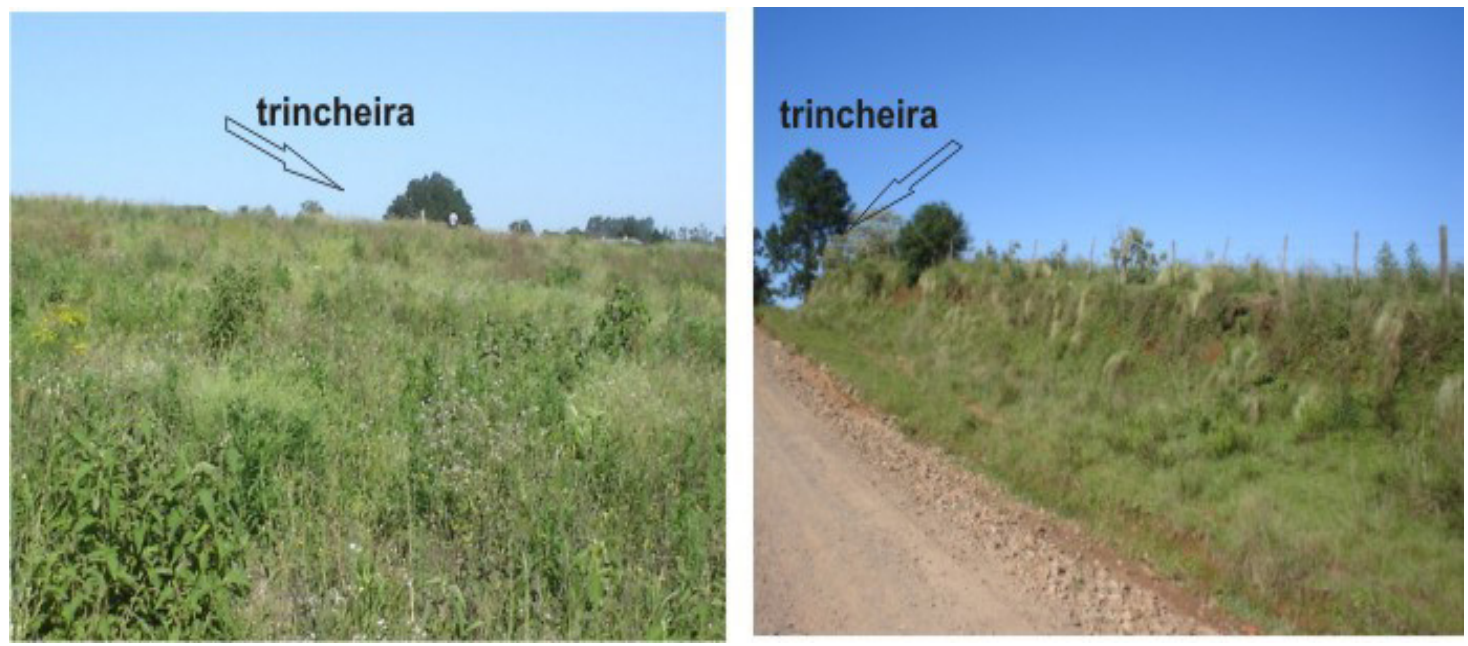

Figura 3: Aspecto geral da paisagem da área onde ocorre um ARGISSOLO VERMELHO Distrófico arênico e de onde foi aberta uma trincheira, descritos os volumes pedológicos e retiradas as amostras para a realização dos ensaios no laboratório.

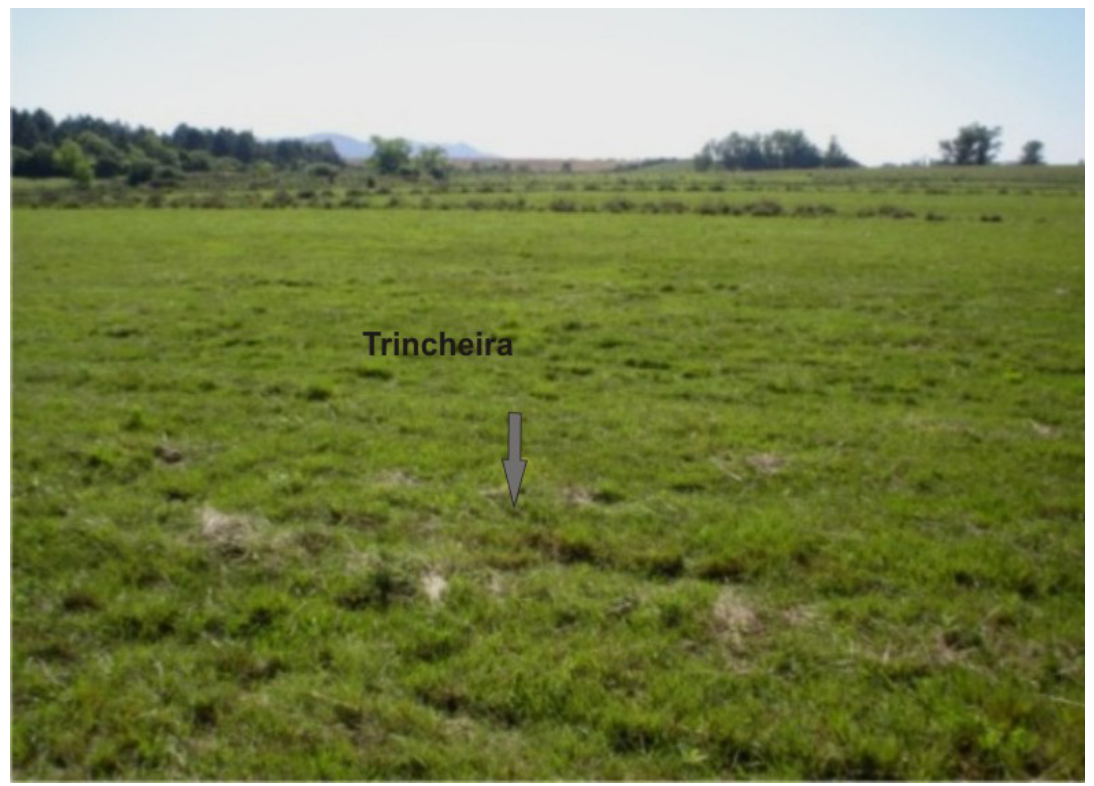

Figura 4: Aspecto da área próxima ao talvegue principal onde ocorre um PLANOSSOLO HIDROMÓRFICO Eutrófico arênico e, em que foi descrito o volume pedológico 4, de onde foram coletadas amostras para a realização dos ensaios em laboratório.

retiradas as amostras para a realização dos ensaios em laboratório. A figura 3 ilustra o aspecto geral da paisagem da área onde ocorre um ARGISSOLO VERMELHO Distrófico arênico e foram descritos os volumes pedológicos e retiradas as amostras para a realização dos ensaios no laboratório. A figura 4 mostra o aspecto geral da área próxima ao talvegue principal onde predominam os depósitos aluvionais que constituem o volume 4 . Os ensaios foram realizados no Laboratório de Sedimentologia do Departamento de Geociências da Universidade Federal de Santa Maria. A partir dos ensaios realizados, os parâmetros físicos determinados foram a distribuição do tamanho de partículas (análise granulométrica), densidade de partículas $(\gamma s)$, densidade aparente $(\gamma d)$, densidade aparente natural ( $\gamma d$ nat), condutividade hidráulica (K), índice de vazios (e), índice de vazios máximo (e máx), índice de vazios mínimo (e min), Grau de compacidade (GC), porosidade (n). Também foram determinados os limites de consistência: limite de contração (LC), limite de plasticidade (LP), limite de liquidez (LL) além do índice de plasticidade (IP).

O traçado da topossequência foi determinado a partir da abertura da trincheira próxima ao divisor topográfico da vertente (A e B) e subsequentes pon- 
tos de amostragens (sondagens a trado) ao longo do segmento da vertente. Em cada ponto amostrado, foi determinado o ângulo do desnível topográfico com o auxílio de um clinômetro. Ainda, para a determinação do grau de declive em cada segmento do perfil da vertente, foi considerada a distância entre esses pontos amostrados. O desnível foi obtido pela equação:

$$
\operatorname{Tg} \infty=\frac{h}{d} \therefore h=d . \operatorname{Tg} \infty
$$

Onde: $\operatorname{Tg} \infty=$ tangente do ângulo; $h=$ desnível topográfico (altura) e $d=$ distância entre as tradagens.

Com os dados relativos ao desnível entre a trincheira e cada ponto de amostragem por tradagem e conhecidas a distâncias entre esses pontos, foi elaborado o perfil topográfico da vertente. As informações relativas à espessura de cada volume pedológico, representadas sobre o perfil topográfico, permitiram a representação bidimensional da topossequência da vertente, conforme pode ser visualizado na figura 5 .

Foram coletadas amostras deformadas (foram coletadas, etiquetadas e armazenadas em saco plástico para serem conduzidas ao laboratório) com $500 \mathrm{~g} \mathrm{em}$ cada um dos volumes pedológicos descritos, para a determinação do tamanho de partículas e os limites de consistência. Além destas, foram coletadas nos mesmos pontos de cada volume pedológico, amostras indeformadas (foram coletadas em anéis de ferro com volume e peso conhecido) para a determinação da densidade de partículas ( $y s)$, densidade aparente $(y d)$, densidade aparente natural ( $y$ dnat ) e condutividade hidráulica (K). Para a determinação do tamanho de partículas da fração areia, utilizou-se o processo por peneiramento e, para as partículas da fração silte e argila, a sedimentação, conforme NBR 7181/84. Oíndice de vazios (e), índice de vazios máximo (e máx), índice de vazios mínimo (e min), o grau de compacidade (GC) e a porosidade (n) foram obtidos através da aplicação de equações.

Para a determinação do tamanho de partículas da fração areia, utilizou-se o processo por peneiramento e, para as partículas da fração silte e argila, a sedimentação, conforme NBR 7181/84.

O grau de compacidade (GC) foi determinado através da expressão (Vargas,1977; Caputo,1988; Holtz; Kovacs,1981):

$$
G C=\frac{e m a ́ x-e n a t}{e m a ́ x-e \min }
$$

onde: $G=$ grau de compacidade; emáx = índice de vazios máximo; $e$ min =índice de vazios mínimo; enat $=$ densidade do solo $(y d)$.

A densidade aparente do solo $(y d)$ foi obtida pela expressão:

$$
y d=\frac{w s}{v}
$$

onde: $y d=$ densidade aparente do solo, $\mathrm{g} \mathrm{cm}^{-3} ;$ wS = massa dos sólidos seca, $\mathrm{g} \mathrm{cm}^{-3} \mathrm{e} v=$ volume total da amostra, $\mathrm{g} \mathrm{cm}^{-3}$.

A densidade aparente natural do solo ( $y$ dnat ) foi obtida pela expressão:

$$
y d n a t=\frac{w s}{v}
$$

onde: $y d n a t=$ densidade aparente natural do solo, $\mathrm{g}$ $\mathrm{cm}^{-3} ; w s=$ massa dos sólidos com a umidade natural, $\mathrm{g} \mathrm{cm}^{-3}$ e $v=$ volume total da amostra, $\mathrm{g} \mathrm{cm}^{-3}$.

A densidade de partículas do solo ( $y s$ ) foi obtida pela expressão:

$$
y s=\frac{w s}{v}
$$

onde: $y s=$ densidade de partículas do solo, $\mathrm{g} \mathrm{cm}^{-3}$; $W S=$ massa das partículas, $\mathrm{g} \mathrm{cm}^{-3} \mathrm{e} v=$ volume das partículas, $\mathrm{g} \mathrm{cm}^{-3}$.

A determinação do índice de vazios máximo e índice de vazios mínimo foi dada pelas expressões:

$$
\begin{array}{ll}
\text { emáx }=\frac{y s}{y s \min }-1 & \text { (equação 6) } \\
e \min =(y s / y s m a ́ x)-1 & \text { (equação 7) }
\end{array}
$$

onde: $y S=$ densidade da amostra do solo determinada de acordo com a ABNT-NBR 6508/80, em $\mathrm{g} \mathrm{cm}^{-3} ;$ ys $\min =$ densidade do solo seco mínima do solo, em $\mathrm{g} \mathrm{cm}^{-3} ;$ ysmáx $=$ densidade do solo seco máxima da amostra de solo, em $\mathrm{g} \mathrm{cm}^{-3}$. 
O índice de vazios foi obtido pela expressão:

$$
e=\frac{n}{(1-n)}
$$

onde: $e=$ índice de vazios e $n=$ porosidade total dada pela expressão:

$$
\left(1-\left(\frac{\gamma s}{\gamma d}\right)\right.
$$

onde: $y s=$ densidade da amostra do solo determi-

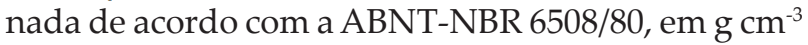
e $y d=$ densidade aparente do solo, $\mathrm{g} \mathrm{cm}^{-3}$.

Para a determinação da condutividade hidráulica foram coletadas, em cada volume pedológico, amostras indeformadas utilizando-se um extrator do solo de Uhland. No laboratório, as amostras foram preparadas e saturadas por um período de 24 horas e, após, submetidas ao ensaio onde, num permeâmetro, foram colocadas as amostras, coletado e medido o volume de água percolada sendo a vazão calculada pela expressão:

$$
K=Q \cdot \frac{L}{A} \cdot H \cdot T
$$

(equação 10)

onde: $\mathrm{K}=$ condutividade hidráulica em $\mathrm{cm} / \mathrm{h} ; \mathrm{Q}=$ volume percolado; $\mathrm{L}=$ altura do bloco da amostra; $\mathrm{H}=$ altura do bloco da amostra e da coluna; $\mathrm{A}=$ área do cilindro; $\mathrm{T}$ = tempo de percolação.

Foi considerado como condutividade hidráulica o resultado calculado pela equação 10.

Os limites de consistência foram determinados em três repetições. O limite de liquidez foi determinado utilizando-se o aparelho Casagrande, segundo a NBR 6459/84, o limite de plasticidade foi obtido conforme a NBR 6457/84 e o limite de contração foi obtido a partir da NBR 6457. O índice de Plasticidade foi obtido a partir da equação:

$$
I P=L L-L P
$$

onde: $I P=$ Índice de Plasticidade; $L L=$ Limite de Liquidez; $L P=$ Limite de Plasticidade.

O limite de contração (LC) foi determinado através da expressão:

$$
L C=w o-y w \cdot(v \circ-v f) w s
$$

onde: $L C=$ limite de contração; $w O=$ teor de água de moldagem do corpo de prova; $y w=$ densidade da água $\left(\mathrm{g} \mathrm{cm}^{-3}\right) ; W S=$ massa dos sólidos $\left(\mathrm{g} \mathrm{cm}^{-3}\right) ; v \circ=$ volume inicial da pastilha $\left(\mathrm{cm}^{3}\right) ; v f=$ volume final da pastilha seca $\left(\mathrm{cm}^{3}\right)$.

A determinação do $L C$ segue inicialmente a preparação de uma pasta com umidade próxima do $L L$ e que é colocado num recipiente próprio e extraído o ar contido na amostra. Em seguida, essa amostra é seca ao ar e depois em estufa. O volume da pastilha seca é obtido imergindo-a em mercúrio e determinando o volume do mercúrio extravasado.

\section{Resultados e discussão}

O relevo é o resultado da atuação de processos naturais que ocorrem na superfície terrestre, sendo caracterizado pelo conjunto de superfícies geomórficas. Ao considerar que a evolução morfogenética das vertentes apresenta estreita relação com o fluxo superficial e subsuperficial da água, a evolução do perfil e da forma da vertente traduz a atuação dos morfogenéticos que atuam no modelado da vertente. O movimento de água contribui com estes processos através do transporte de materiais das partes mais elevadas para as mais baixas (processos de degradação e agradação), que acontecem em superfície e internamente ao longo da vertente. Nesse sentido discute-se que a instalação preferencial das ravinas e voçorocas, dissecando o relevo ao longo da vertente, dá-se nos diferentes segmentos de vertentes (côncavos, convexos, retilíneos, côncavos-convexos, convexos-côncavos, resultando no perfil e forma desses segmentos de vertentes). Entretanto, quando a instalação de canais incisivos (sulcos, ravinas e voçorocas) acontece em cabeceiras de drenagens, nas rupturas de declive e no terço inferior dos segmentos convexos de vertente, eles revelam uma forma da ação morfogenética das águas superficiais e subsuperficiais.

Pela análise da figura 5, observa-se que o perfil da topossequência se apresenta desde o topo em direção à base, como côncavo-convexo-côncavo. Portanto, evolui de um perfil côncavo na porção superior da vertente para um perfil convexo no segmento médio das vertentes e novamente convexo próximo da base, evidenciando que a maior perda por denudação acontece na porção convexa dos segmentos. Assim, o perfil da vertente evolui para uma forma côncava. O segmento intermediário da vertente mostra uma ruptura na encosta da vertente e, neste ponto, também deixa de existir o volume pedológico 2. Isso indica que nesse setor aflora o fluxo subsuperficial da água 
e esse processo de exfiltração desencadeia colapsos na superfície da vertente. Também nesse segmento (convexo) da vertente, o volume 3 está mais próximo da superfície, indicando uma maior remoção por perdas superficiais do volume 1 . Nos dois lados da topossequência (vertente A e vertente B), o comportamento mostra-se semelhante, embora as vertentes apresentem diferentes declividades, dimensão e espessura dos volumes. Ambas convergem para o talvegue principal, junto à várzea, cuja deposição constitui o volume 4 .

A partir do traçado e representação da topossequência, ilustrada na figura 5, pode-se observar um desnível vertical de 9 metros e uma distância horizontal, desde o divisor topográfico até o curso d'água junto a base da vertente, de 440 metros para a vertente A e 200 metros para a vertente $B$. Ao longo dessa superfície da topossequência, são observados pequenos ressaltos topográficos que podem estar relacionados com a composição do substrato litológico como também aos colapsos ocorridos na superfície da vertente.

O segmento da vertente próximo da base assume uma conformação côncava. Essa conforma- ção, como já abordado, está relacionada a processos de exfiltração da água que ocorrem nesse setor da vertente, quando o volume pedológico 2 aflora a superfície. Isso fica evidente quando se observa que esse volume (volume 2) apresenta o maior valor para a condutividade hidráulica, além disso, a presença de alto teor de argila do volume 3 promove uma diminuição da velocidade na infiltração vertical, o que facilita o fluxo lateral de escoamento em sub-superfície.

Os quadros 1 e 2 mostram a descrição morfológica dos volumes pedológicos identificados na topossequência (trincheira 1, T1 e trincheira 2, T2), selecionada como representativa para as vertentes que ocorrem área experimental do Departamento de Solos, no Campus da Universidade Federal de Santa Maria. Os dados das tabelas 1 e 2 trazem os resultados obtidos para a distribuição granulométrica e limites de consistência para os volumes pedológicos descritos. As figura 6 e 7 mostram as respectivas curvas granulométricas. A tabela 3 mostra os limites de consistência obtidos e as tabelas 4 e 5 trazem os resultados obtidos para os demais índices físicos determinados.

Vertente B

Vertente A

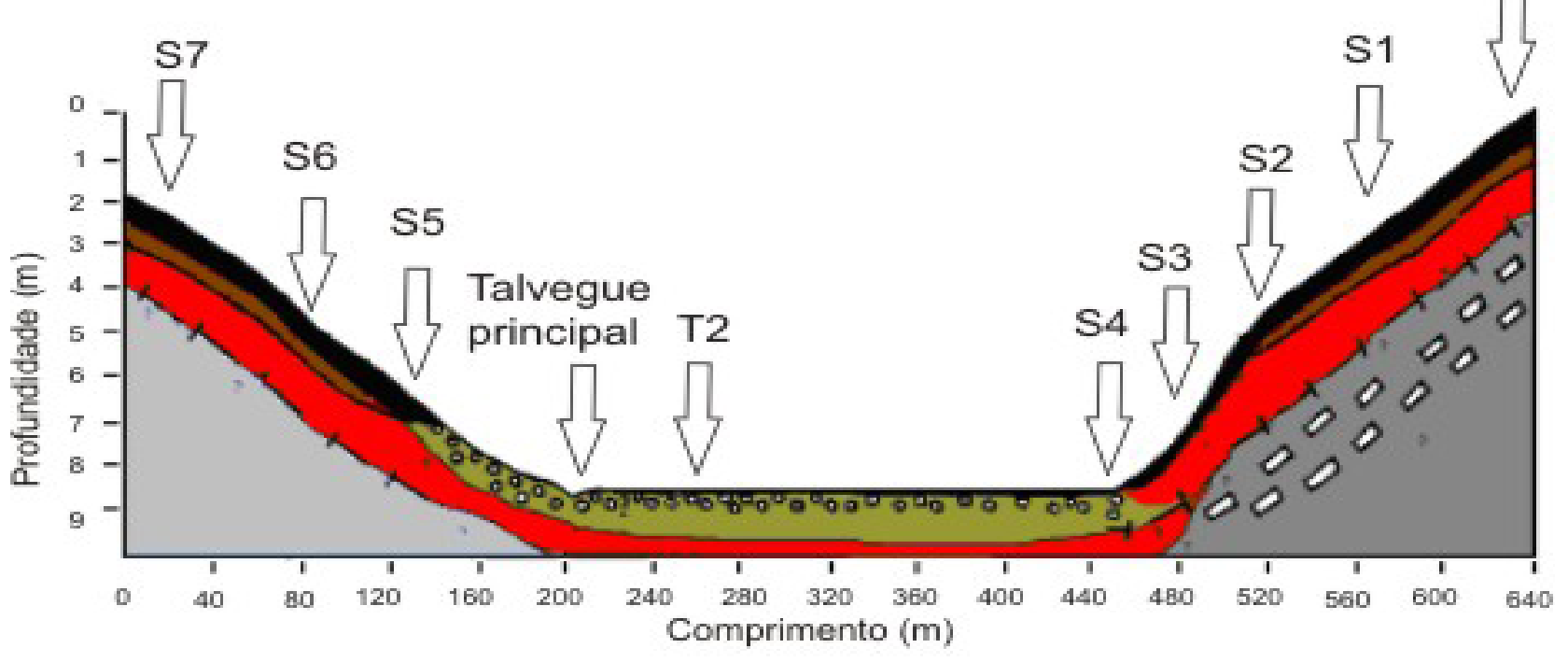

Legenda

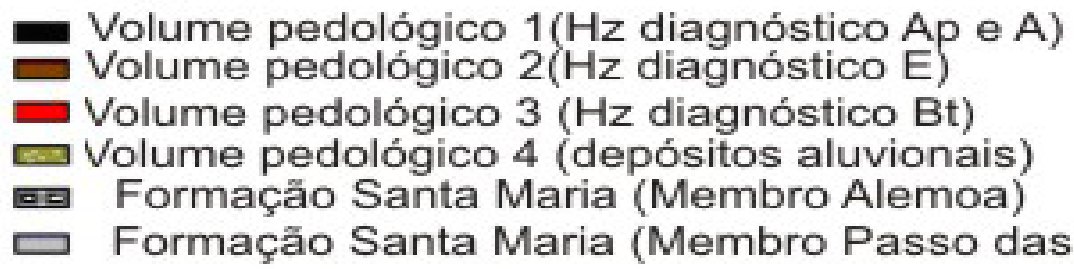

$\mathrm{S}=$ Sondagem $\mathrm{a}$ trado

$\mathrm{T}=$ Trincheira

$\mathrm{Hz}=$ horizonte

Formação Santa Maria (Membro Passo das Tropas)

Figura 5: Aspecto bidimensional da topossequência selecionada como representativa das vertentes que ocorrem área experimental do Departamento de Solos, no Campus da Universidade Federal de Santa Maria. 
Quadro 1 - Descrição morfológica dos volumes pedológicos conforme Lemos; Santos (1993): Vertente A.

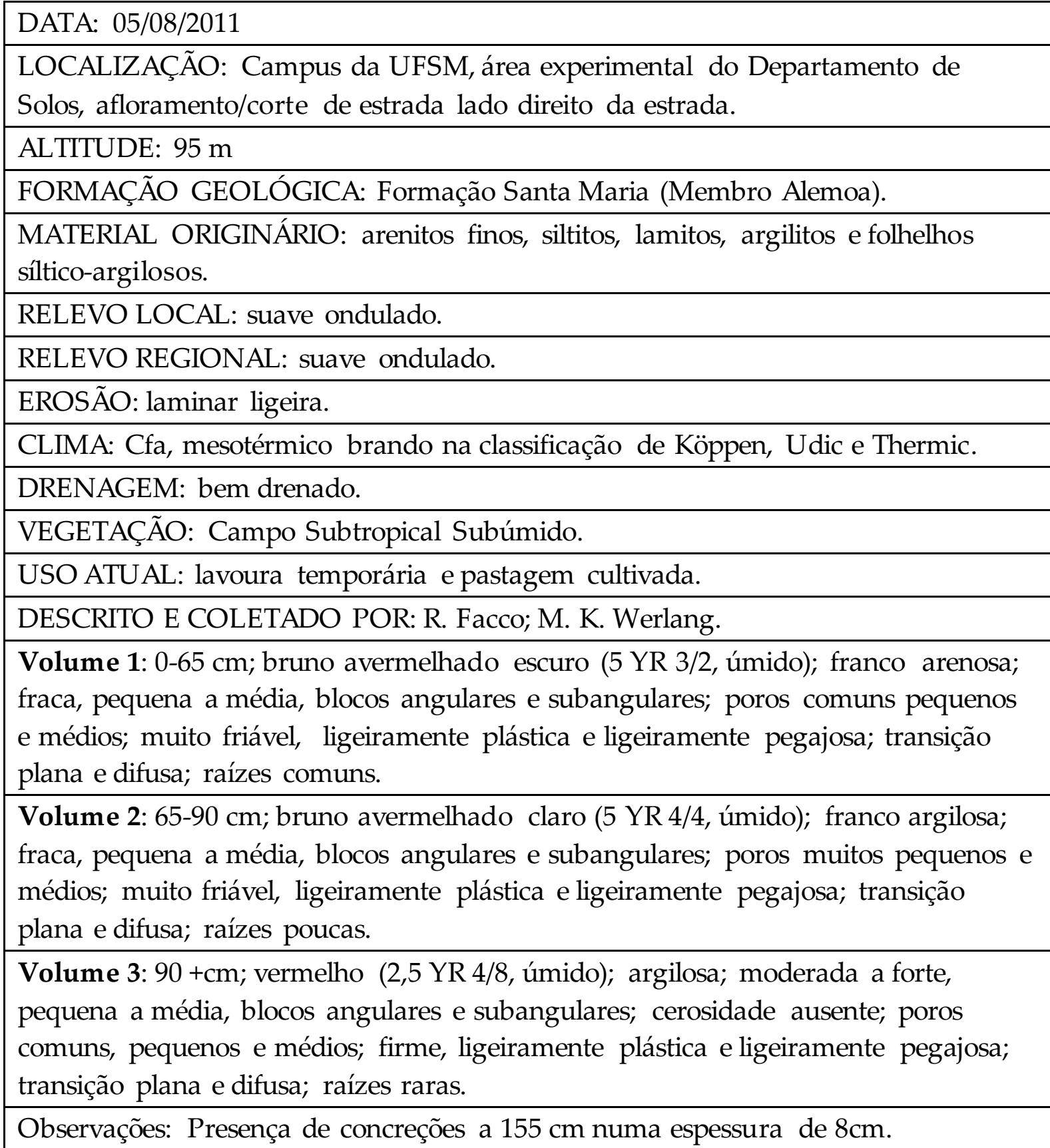


Quadro 2 - Descrição morfológica dos volumes pedológicos conforme Lemos; Santos (1993): Vertente B.

DATA: 05/08/2010

LOCALIZAÇÃO: Campus da UFSM, área experimental do Departamento de Solos em trincheira cavada no terço superior da vertente.

ALTITUDE: $105 \mathrm{~m}$

FORMAÇÃO GEOLÓGICA: Formação Santa Maria (Membro Passo das Tropas).

MATERIAL ORIGINÁRIO: arenitos de granulação média a gróssea.

RELEVO LOCAL: Suave ondulado.

RELEVO REGIONAL: Suave ondulado.

EROSÃO: laminar ligeira.

CLIMA: Cfa, mesotérmico brando na classificação de Köppen, Udic e Thermic

DRENAGEM: Bem drenado

VEGETAÇÃO: Campo Subtropical Subúmido

USO ATUAL: Lavoura temporária

DESCRITO E COLETADO POR: R. Facco; M. K. Werlang.

Volume 1: 0-52 cm; bruno avermelhado escuro (5 YR 3/4, úmido); franco arenosa; fraca, pequena a média, blocos angulares e subangulares; poros comuns pequenos e médios; muito friável, ligeiramente plástica e ligeiramente pegajosa; transição plana e difusa; raízes comuns.

Volume 2: $52-79 \mathrm{~cm}$; bruno avermelhado claro (5 YR 4/8, úmido);franco argilosa; fraca, pequena a média, blocos angulares e subangulares; poros muitos pequenos e médios; muito friável, ligeiramente plástica e ligeiramente pegajosa; transição plana e difusa; raízes poucas.

Volume 3: 79-110 cm; vermelho (2,5 YR 4/6, úmido); argilosa; moderada a forte, pequena a média, blocos angulares e subangulares; cerosidade ausente; poros comuns, pequenos e médios; firme, ligeiramente plástica e ligeiramente pegajosa; transição plana e difusa; raízes raras.

Volume 4: $110+\mathrm{cm}$; bruno acinzentado (5 YR 6/6, úmido); silte-argilosa; moderada a forte, pequena a média, blocos angulares e subangulares; cerosidade ausente; poros comuns, pequenos e médios; firme, ligeiramente plástica e ligeiramente pegajosa; transição plana e difusa; raízes raras. 
Tabela 1: Análise granulométrica: vertente A.

\begin{tabular}{cccccc}
\hline & & \multicolumn{4}{c}{ Composição granulométrica da terra fina $\left(\mathrm{g}^{*} \mathrm{~kg}^{-1}\right)$} \\
\hline & Prof. $(\mathrm{cm})$ & Areia grossa & Areia fina & Silte & Argila \\
\hline 1 & $0-65$ & 243 & 327 & 266 & 163 \\
\hline 2 & $65-90$ & 187 & 343 & 329 & 140 \\
\hline 3 & $90+$ & 120 & 215 & 193 & 472 \\
\hline
\end{tabular}

Tabela 2: Análise granulométrica: vertente B.

\begin{tabular}{cccccc}
\hline \multirow{2}{*}{ Horizontes/(volumes) } & & \multicolumn{2}{c}{ Composição granulométrica da terra fina $\left(\mathrm{g} . \mathrm{kg}^{-1}\right)$} \\
\hline & Prof(cm) & Areia grossa & Areia fina & Silte & Argila \\
\hline 1 & $0-52$ & 54 & 173 & 499 & 273 \\
\hline 2 & $52-79$ & 204 & 321 & 308 & 462 \\
\hline 3 & $79-110$ & 28 & 92 & 472 & 407 \\
\hline 4 & $110+$ & 23 & 142 & 362 & 474 \\
\hline
\end{tabular}

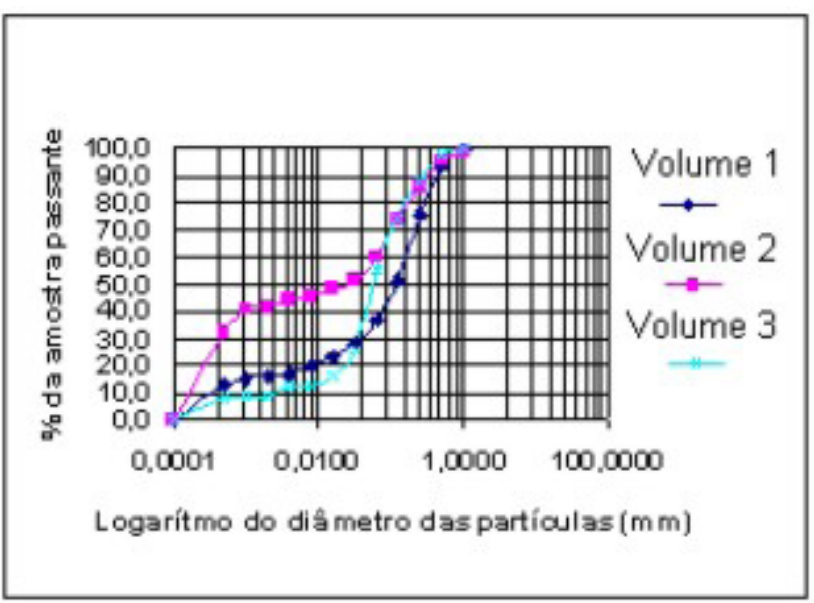

Figura 6: Curvas granulométricas: vertente A.

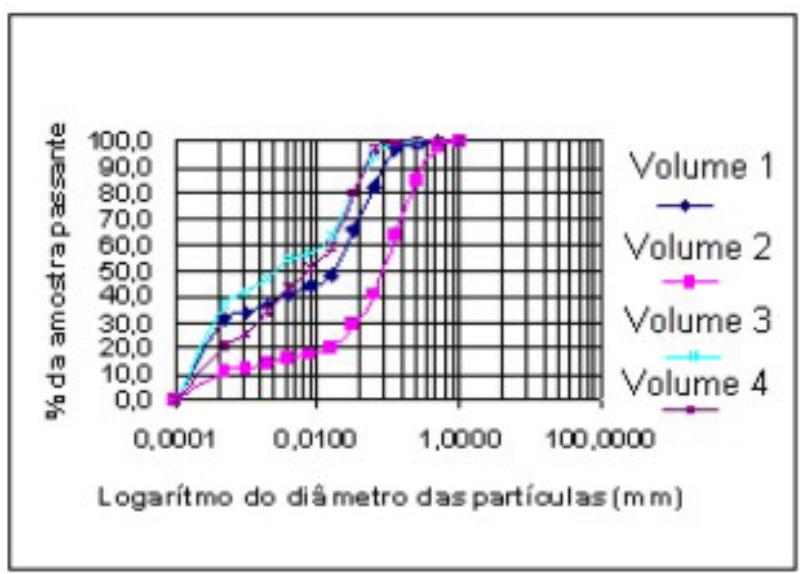

Figura 7: Curvas granulométricas: vertente B. 
Tabela 3: Vertente B: Resultados obtidos para os limites de consistência.

\begin{tabular}{cccccc}
\hline & \multicolumn{4}{c}{ Limites de consistência } \\
\hline & Prof.(cm) & LL & LP & LC & - \\
\hline 1 & $0-52$ & NP & NP & - \\
\hline 2 & $52-79$ & NP & NP & - & 25,82 \\
\hline 3 & $79-110$ & 44,50 & 18,68 & 18,12 & 28,80 \\
\hline 4 & $110+$ & 46,00 & 18,20 & 18,00 & 2 \\
\hline
\end{tabular}

(LL=limite de liquidez; LP=limite de plasticidade; LC=limite de contração; IP=índice de plasticidade).

Tabela 4: Vertente B: Resultados obtidos para os índices físicos.

\begin{tabular}{ccccccccc}
\hline \multirow{2}{*}{$\begin{array}{c}\text { Horizontes/ (volumes) } \\
\text { Prof.(cm) }\end{array}$} & e Max & yd & e min & ys & ydnat & GC\% \\
\hline 1 & $0-52$ & 1,16 & 1,46 & 0,85 & 2,63 & 1,66 & 1,16 \\
\hline 2 & $52-79$ & 0,92 & 1,56 & 0,60 & 2,65 & 1,73 & 0,71 \\
\hline 3 & $79-110$ & 1,51 & 1,46 & 1,11 & 2,74 & 1,79 & 1,60 \\
\hline 4 & $110+$ & 1,34 & 1,56 & 1,01 & 2,69 & 1,91 & 1,87 \\
\hline
\end{tabular}

(eMax=índice máximo de vazios ( $\mathrm{g} \mathrm{cm}-3)$; yd =densidade aparente $(\mathrm{g} \mathrm{cm}-3)$; emin=índice mínimo de vazios(g cm-3); GC\%=grau de compacidade; $y s=$ densidade de partículas $(\mathrm{g} \mathrm{cm} \mathrm{-3);} \mathrm{ydnat} \mathrm{=densidade} \mathrm{aparente} \mathrm{natural}(\mathrm{gcm}-3)$.

Tabela 5: Vertente B: Resultados obtidos para o índice de vazios, porosidade total e condutividade hidráulica.

\begin{tabular}{ccccc}
\hline \multicolumn{2}{c|}{ Horizontes/ (volumes) } & \multicolumn{2}{c}{ Índices } \\
\hline & Prof.(cm) & $\mathrm{e}$ & $\mathrm{n}$ & $\mathrm{K}$ \\
\hline 1 & $0-52$ & 0,80 & 44,44 & 5,22 \\
\hline 2 & $52-79$ & 0,69 & 40,82 & 6,96 \\
\hline 3 & $79-110$ & 0,87 & 46,52 & 0,74 \\
\hline 4 & $110+$ & 0,72 & 41,82 & 1,79 \\
\hline
\end{tabular}

e=índice de vazios (\%); $\mathrm{n}=$ porosidade total(\%); K=condutividade hidráulica saturada $(\mathrm{cm} / \mathrm{h})$.

Os resultados obtidos (tabela 1 e 2) indicam um incremento no teor de argila com o aumento da profundidade (exceto para o volume 2, que apresenta elevado teor de areia e silte). As curvas granulométricas (figuras 6 e 7) indicam a presença de material mal graduado, por consequência, elevado potencial erosivo. Os dados relativos a consistência mostram os volumes superficiais não plásticos. Os volumes $3 \mathrm{e}$ 4 apresentam resultados semelhantes em relação aos limites de consistência (tabela 3 ) indicando a relação entre a plasticidade e o teor de argila presente. Em relação aos demais índices físicos (tabelas 4 e 5) observa-se que os volumes 2 e 1 , respectivamente, apresentam os maiores valores para a condutividade hidráulica. $\mathrm{O}$ volume 3 apresenta a mais baixa condutividade e, comparativamente aos demais, elevada densidade e compactação. Isso indica que nos volumes superficiais há uma maior facilidade de infiltração vertical, sobretudo no volume 2. Essa facilidade na infiltração tende a diminuir, quando atinge o volume 3 , promo- 
vendo aumento no processo de exfiltração lateral ao longo dos segmentos da vertente. Essa condição do comportamento do manto pedológico influencia no processo de infiltração/exfiltração da água, refletindo no comportamento morfodinâmico dos segmentos da vertente. Esse reflexo pode ser verificado pelas inflexões observadas no perfil dessas vertentes (A e B). As figuras 8 e 9 ilustram esse processo de infiltração/ exfiltração da água no segmento côncavo da vertente A (S3) e vertente B (S6), ilustrado pela figura 3. Os segmentos côncavos das vertentes estudadas apresentaram uma menor espessura no volume 1 . Neles, também, nota-se que ocorre uma maior exfiltração da água. Aliado aos resultados dos índices físicos obtidos para o manto pedológico, faz considerar que a maior intensidade de denudação acontece nesses segmentos dessas vertentes.

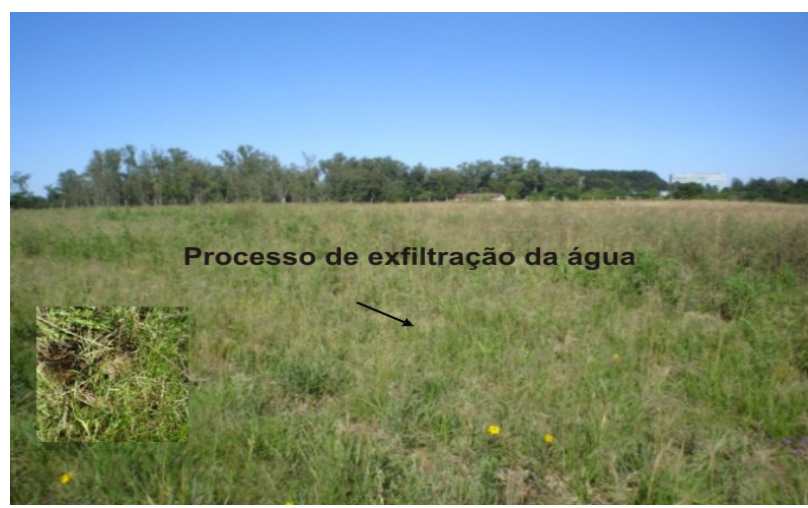

Figura 8: Aspecto da vertente selecionada como representativa das vertentes que ocorrem área experimental do Departamento de Solos, no Campus da Universidade Federal de Santa Maria onde, no detalhe, pode ser observado o processo de exfiltração da água que ocorre em num dos pontos de inflexão do segmento côncavo da vertente A.

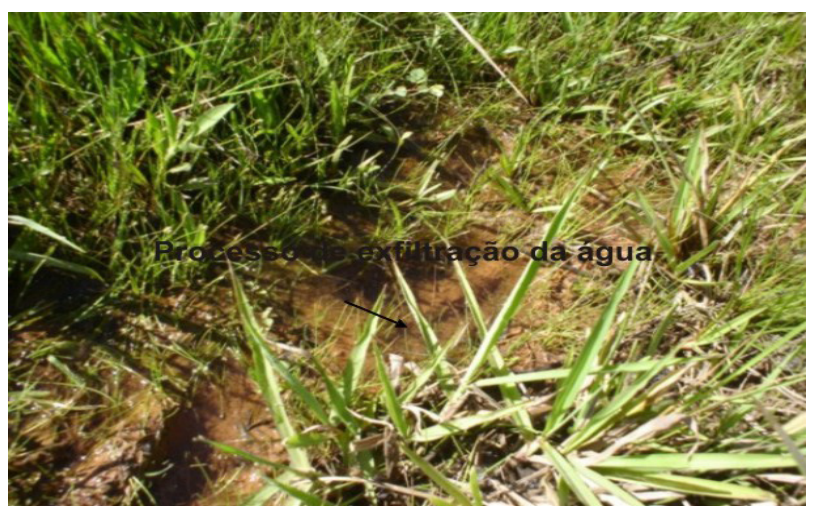

Figura 9: Ponto da vertente A (S3), na interface do volume 2 com o volume 3 mostrando o processo de exfiltração de água intenso que ocorre no segmento côncavo da vertente.

Nesse sentido, os maiores valores para a condutividade hidráulica do volume 2 e a mais baixa condutividade hidráulica obtida para o volume 3 indicam o comportamento do fluxo subsuperficial da água ao longo da vertente, numa condição do processo de infiltração/exfiltração da água. Isso reflete no comportamento morfodinâmico das vertentes da topossequência estudada. Além desses resultados, as menores espessuras do volume 1 , nos segmentos côncavos das vertentes estudadas, permitem concluir que as vertentes apresentam uma dinâmica de denudação relacionada aos processos de infiltração/exfiltração da água ao longo dessa topossequência. Assim, a maior perda por denudação acontece nos segmentos côncavos das vertentes. A maior convexidade na porção superior e a maior concavidade na porção inferior da vertente relacionam-se à remoção de sedimentos do volume 1 do manto pedológico. Também é possível afirmar que os processos de erosão hídrica, em subsuperfície, atuam de forma mais incisiva na interface entre o volume 2 com o 3, revelando ser este o setor do perfil da vertente com maior fragilidade frente a atuação de processos erosivos. Pode-se ainda afirmar que a concavidade apresentada em alguns dos segmentos do perfil da vertente, está relacionada com a exfiltração da água em face das propriedades apresentadas pelos volumes pedológicos. Portanto, as propriedades da cobertura pedológica exercem forte influência na conformação do perfil das vertentes da topossequência estudada.

\section{Conclusão}

Ao estabelecer uma compartimentação da topossequência das vertentes, desde o divisor orográfico até o talvegue, foi possível observar que o comportamento da cobertura pedológica, nos segmentos de vertente, exerce influência morfogenética nessas vertentes estudadas. A partir da morfologia dos volumes pedológicos descritos nas trincheiras e, ao realizar sondagens a trado em diferentes segmentos das vertentes, bem como a análise de resultados dos ensaios obtidos no laboratório, foi possível avaliar que algumas propriedades físicas e dinâmicas dos horizontes diagnósticos, que no trabalho foram considerados "volumes pedológicos", influenciam na morfogênese das vertentes e definem a conformação do perfil dessas vertentes.

\section{Referências}

AB'SÁBER, A.N. Um conceito de geomorfologia a serviço das pesquisas sobre o quaternário. Geomorfologia.Instituto de geografia/USP: São Paulo; n.18, 1969. 
ABNT-ASSOCIAÇÃO BRASILEIRA DE NORMAS TÉCNICAS. Solo-determinação do índice de vazios mínimo de solos não coesivos: NBR 12051. Rio de Janeiro, fev. 1991.

\section{ABNT-ASSOCIAÇÃO BRASILEIRA DE NORMAS} TÉCNICAS. Solo-determinação do índice de vazios máximo de solos não coesivos: NBR 12004. Rio de Janeiro, nov. 1990

ABNT-ASSOCIAÇÃO BRASILEIRA DE NORMAS TÉCNICAS. Solo-determinação do limite de liquidez: NBR 6459. Rio de Janeiro, 1984.

\section{ABNT-ASSOCIAÇÃO BRASILEIRA DE NORMAS TÉCNICAS. Solo-determinação do limite de plasticidade: NBR 6457. Rio de Janeiro, 1984.}

ABNT-ASSOCIAÇÃO BRASILEIRA DE NORMAS TÉCNICAS. Solo-determinação do limite de contração: NBR 6508. Rio de Janeiro, 1980.

ABNT-ASSOCIAÇÃO BRASILEIRA DE NORMAS TÉCNICAS. Solo-determinação da distribuição do tamanho de partículas: NBR 7181. Rio de Janeiro, 1984.

AYOADE, J. Introdução a climatologia dos trópicos. São Paulo-SP: Difel, 1986.

BERTRAND, G. Paisagem e geografia física global - esboço metodológico. Cadernos de ciências da terra. Instituto de geografia/USP: São Paulo; 1971.

BERTRAND, G. Paysage et géographie physique globale: Esquisse méthodologique. Revue Géographique des Pyrénées et du Sud-Ovest. Toulouse; 39(3), 249-272,1968.

BORTOLUZZI, C.A. Contribuição à Geologia da Região de Santa Maria, Rio Grande do Sul, Brasil. Pesquisas. Porto Alegre-RS: v. 4, n. 1, p.7-86, 1974.

BOULET, R. Toposéquences de sols tropicaux en Haute Volta: équilibres et deséquilibres pédobioclimatiques., Mém. ORSTOM,. v.85, 1978.

BOULET, R.; BRUGIÈRE, J.M.; HUMBEL, F.X. Relations entre organization des sols et dynamique de l'eau en Guyane Française Septentrionale. Sci. Sol, 1:3-18, 1979.
BOULET, R.; CHAUVEL, A.; HUMBEL, F.X. ; LUCAS, Y. Analyse structurale et cartographie en pédologie: I - Prise en compte de l'organisation bidimensionelle de la couverture pédologique: les études de toposéquences et leurs principaux apports à la connaissance dês sols. Cah. ORSTOM, Sér. Pédol., 19:309-321, 1982.

BOCQUIER, G. 1973. Genèse et évolution de deux toposéquences de sols tropicaux du Tchad. Paris: ORSTOM, 350 p. (Mémoires, 62).

CAPUTO, H. P. Mecânica dos solos e suas aplicações: Fundamentos. 6. ed. v.1. Rio de Janeiro-RJ: Livros Técnicos e Científicos Editora, 1988.

\section{CARVALHO, 1970. A study of Terra Roxa}

Estruturada and Latossolo Roxo on a topographic sequence in São Paulo State, Brazil. University New Castle upon Tyne, New Castle upon Tyne, Thesis Master Science, 93p.

\section{CHAUVEL, A. 1972. Observation}

micromorphologique de la partie supérieure des sols rouges ferralitiques de Casamance (Sénégal). Essai d'interprétation de la dynamique actuelle, sous couverture forestier. Cahiers Orstom, Série Pédologie, 10: 343-356.

CHAUVEL, A. Recherches sur la transformation des sols ferralitiques de la zone tropicale à saisons contrastées. Paris, 1977. 532 p. Tese Université de Strasburg.

DOKUCHAEV, V.V. 1893. The Russian steppes and study of the soil in Russia, its past, and present. St Petersburg, Dept Agric. Min. Crown Domains.

DREW, D. Processos Interativos Homem-Meio Ambiente. Rio de Janeiro: Bertrand Brasil, 1988.

HOLTZ, R.D.; KOVACS, W.D. An introduction to geotechnical engineering. New Jersey: PrenticeHael, 1981.

LEMOS, R.C.; SANTOS, R.D. dos. Manual de descrição e coleta de solo no campo. 3 ed. Campinas: SBCS/SNLCS, 1993.

LEPSCH, I.F.; BUOL, S.W. 1974. Investigations in an Oxisol-Ultisol toposequence in São Paulo State, Brazil. Soil Science Society America Proceedings, 38: 491-496. 
MILNE, G. 1935. Some suggested units of classification and mapping, particularly for east African soils. Soil Research, 4: 183-198.

MONTEIRO, C.A.F. Geossistemas: a história de uma procura. São Paulo: Contexto, 2000.

QUEIROZ NETO, J.P. 1969. Interpretação dos solos da Serra de Santana para fins de classificação. Escola Superior de Agricultura Luiz de Queiroz, Universidade de São Paulo, Piracicaba, Tese de Doutorado, 135p.

QUEIROZ NETO, J.P. Análise estrutural da cobertura pedológica no Brasil. In: CONGRESSO BRASILEIRO DE CIÊNCIA DO SOLO, 21 Campinas, 1988. Anais. Campinas, Sociedade Brasileira de Ciência do Solo, 1988.p.415-430.

QUEIROZ NETO, J.P. Geomorfologia e pedologia. Revista Brasileira de Geomorfologia. 1:59-67, 2000.

SOCHAVA, B. Geographie und ökologie. Geogr. Mitt., Petermanns, XCVI, p. 89-98, 1972.

SOTCHAVA, V. B. O estudo de geossistemas. Métodos em Questão. São Paulo; p. 27-36, 1982.

VARGAS, M. Introdução à mecânica dos solos. São Paulo: Mcgraw-Hill do Brasil, 1977.

VIEIRA, E.F. Rio Grande do Sul. Geografia física e vegetação. Porto Alegre-RS: Sagra, 1984. 